\title{
Effect on high rise structure expose to blast load
}

\author{
Rucha N Patel, M.Tech, Structural Engineering, Ganpat University, India. ruchshnm@gmail.com \\ Prof. Arjun M Butala, Department of Civil Engineering, Ganpat University, India.
} amb03@ganpatuniversity.ac.in

\begin{abstract}
The impression of blast load on building is very important things to consider in a design process. A bomb detonation within structures or straightaway the building can drive damage on the building either in external or internal structural frames, by collapse of walls etc. These kinds of affliction are uncommon and man-made disasters. The impact of blast load is equivalent to a dynamic loads and that demand to take caution while calculating of it. Someone can calculate as other lateral forces like earthquake and wind load. Design fully blast resistant structures is not pragmatic and economic, till the knowledge of mitigating its effect while designing new structures or maintaining old one with its less impact is identical. In this present study, the behavior of G+15 storey RCC structure is analyzed under the blast load with the help of ETAB software. According to the IS code provision, the dead load, live load and wind load has been considered to study the effect of it. Also, the distance of blast and its charge weight is very according to IS 4991-1968.
\end{abstract}

Keywords — blast resistance building, blast loading, stand-off distance, scale distance, denotation charge weight, dynamic pressure, seismic response.

\section{INTRODUCTION}

Terrorism is the most dangerous problem the world is facing today. It has caused the feeling of insecurity among the people despite of the advancement in technology. Safety and security being the most important aspects any building, blast resistance of its structure becomes an important concern for safety. The cost will increase as the safety demands are raised; hence it is very important to choose design which is balancing safety and economy. It impossible to design fully blast proof structure, but it can be designed to sustain reasonable blast load. Despite the fact that the magnitude of the explosion and the loads caused by it cannot be anticipated perfectly, efforts can be made to reduce the consequences of the explosion. Standoff distance is decided based on the premises security and location of the building in the premises. Consideration of this load as design load adds cost to the building but increases safety factor. Designer has to choose a design considering balancing between safety and cost. Different designs will have different performance to blast analysis. Different designs will be investigated and modifications in existing designs or new designs will be proposed having better blast resistance. The proposed design will be analyzed and evaluated for different conditions using analysis and design tools.

Blast analysis is the most important things to know the behavior of building during the blast. Blast load is very important to consider as a design load on building. For the better blast resistance structure some study and research do on the blast behavior. So many literatures available for this study they have do different techniques for blast analysis of structure. And also use the different software for blast analysis of the structure.

I chose a malty storey structure and analyzed my structure in ETABS 2013. Define various loads (dead load, live load, earthquake load) in ETABS software. In dead Load, selfweight multiplier is used 1 to calculate dead load as default. Live load or any other define load, the multiplier is zero.

After defining loads and various load combinations the modal analysis is carried out. Brick wall load is assigned on beams. The brick wall of $230 \mathrm{~mm}$ thickness is considered. The pressure and time for analysis is calculated as per IS 4991:1968 Criteria for Blast Resistant Design OF Structures for Explosions above Ground.

\section{BLAST PHENOMENON \& EXPLOSIONS}

Blast release of energy and hot gases very fast in in milliseconds into the surrounding atmosphere. This explosion caused by the Chemicals (TNT), two chemicals mixing in a high temperature. During blast the hot gases that are generated occupy the space surroundings [1]. Blast load was uniformly distributed load increasing of standoff distance load also decreases. Blasts can be exemplified as physical blast, chemical blast, and nuclear blast. Above the ground surface blast are mainly three different types like air blast, surface blast and high altitude blast. The rapid releasing of energy caused by the wave form of a pressure in the surrounding space is spread as shock front. Due to the 
blast, accumulations of hot gases take place. The absolute maximum pressure over and above the atmospheric pressure take place at the shock wave is known as maximum or peak value of over pressure. Following the shock wave, reduce to around one-half the maximum overpressure and carry through approximately even at the canter of explosion.

\section{A. Blast load and effect on building}

Blasts release of energy and hot gases in milliseconds into the surrounding atmosphere. During blast the hot gases that are generated occupy the space surroundings. Blast load was uniformly distributed load. The fig-1 show the vehicle weapon blast with stand-off distance and blast pressure mansion on it [1].

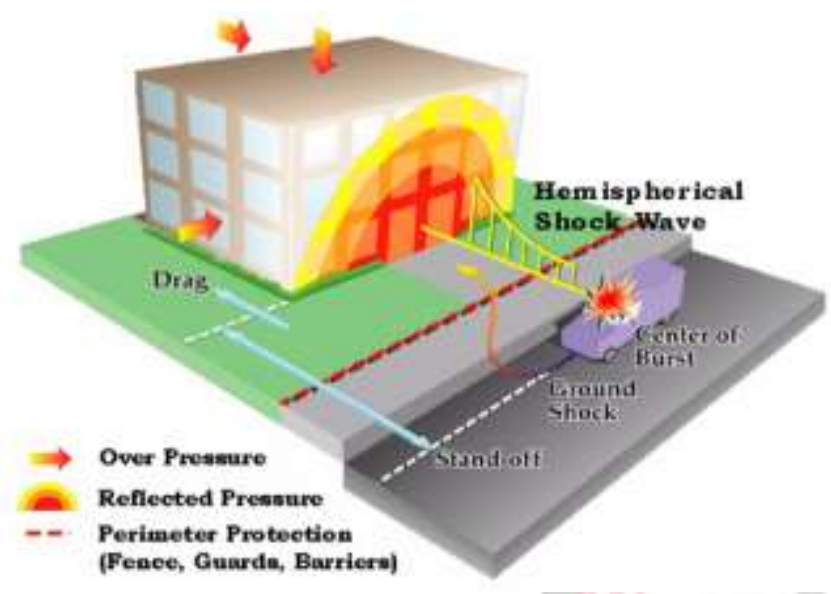

Fig 1: blast load effect on building

It is not possible to declare that blast shall happen in only one direction. Hence safety precautions should be taken from all direction. The highly affected beams and columns because of a blast are that of the basement region. So they are to be strengthened. A feasible way to protect the structure is by providing barrier compound all-round the structure. The process of windows is exterior wall column, lifting up of floors, downward pressure on roof.

\section{B. Blast load profile}

An explosion can be defined as a very fast chemical reaction involving a solid, dust or gas, during which a rapid release of hot gases and energy takes place. The phenomenon lasts only some milliseconds and it results in the production of very high Temperatures and pressures.

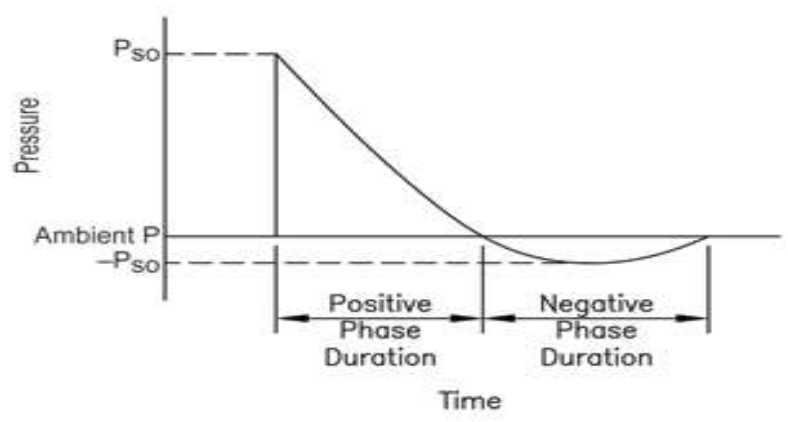

Fig1 shows the idealized profile of the pressure in relation to time for the case of a free air blast wave, which reaches a point at a certain distance from the detonation. The pressure surrounding the element, is initially equal to the ambient pressure Po, and it undergoes an instantaneous increase to a peak pressure Pso at the arrival time tA, when the shock front reaches that point. The time needed for the pressure to reach its peak value is very small and for design purposes it is assumed to be equal to zero [3].

The peak pressure Pso is also known as side-on overpressure or peak overpressure. The value of the peak overpressure and the velocity of propagation of the shock wave decreases with increase in distance from the detonation centre. After its peak value, the pressure decreases with an exponential rate until it reaches the ambient pressure at $\mathrm{tA}+\mathrm{to}$, to being called the positive phase duration. After the positive phase of the pressure-time diagram, the pressure becomes smaller (referred to as negative) than the ambient value, and finally returns to it [3].

The negative phase is longer than the positive one, its minimum pressure value is denoted as Pso - and its duration as to. The negative phase of the explosive wave is usually not taken into account for design purposes as it has been verified that the main structural damage is connected to the positive phase. Additionally, the pressures that are produced from the negative has of the blast wave are relatively small compared to those of the positive phase and since these are in the opposite direction, it is usually on the safe side to assume that they do not have a big impact on the structural integrity of buildings under blast loads[6].

The damage in a building depends on the energy imparted to it through the reflected shock front of explosion, which is contributed by both the positive and negative phases of the pressure-time history. The pressure and hence forces on the building vary in time and space over the exposed surface of the building, depending on the location of the detonation in relation to the building. Therefore, when studying the response of a structure under a specific blast, the location of detonation which produces the most severe effects on the structure should be identified.

\section{MODELING AND ANALYSIS}

In this study, I considered 15 story building. The building is model in ETABS software. Dimension of building $27.5 \mathrm{~m}$ $\mathrm{x} 20 \mathrm{~m}$ with 5 bays in $\mathrm{X}$ direction 5.5 meters and 5 bays in $\mathrm{Y}$ Direction 4 meters respectively. Total height of building is $45.5 \mathrm{~m}$, Floor height $3 \mathrm{~m}$.

Fig 2: blast wave's pressure 


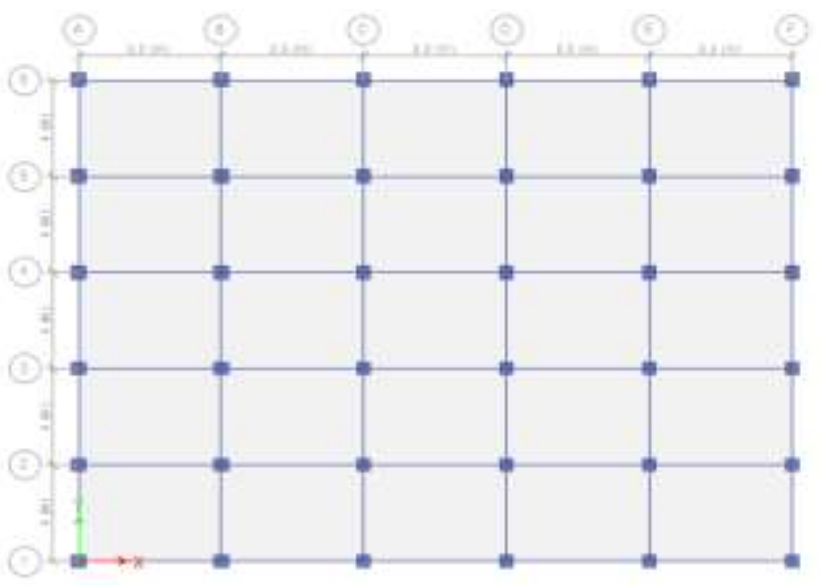

Fig 3: building plan

\section{A. Different cases for analysis}

Case: 1 blast of $200 \mathrm{~kg}$ (TNT) explosive with stand -off distance $21 \mathrm{~m}$

TYPE 1 model - conventional frame structure.

TYPE 2 model - conventional frame structure with increase beam and column size.

TYPE 3 model - convention frame with adding the shear wall at corner and center.

Case: 2 blast of $500 \mathrm{~kg}$ (TNT) explosive with stand -off distance $30 \mathrm{~m}$

TYPE 1 model - conventional frame structure.

TYPE 2 model - conventional frame structure with increase beam and column size.

TYPE 3 model - convention frame with adding the shear wall at corner and center.

Table 1: beam and column size for different model

\begin{tabular}{lccccc}
\hline & $\begin{array}{l}\text { Standof } \\
\text { f dist }\end{array}$ & $\begin{array}{l}\text { Blast } \\
\text { load }\end{array}$ & $\begin{array}{l}\text { Type of } \\
\text { model }\end{array}$ & $\begin{array}{l}\text { Column size } \\
(\mathrm{mm})\end{array}$ & $\begin{array}{l}\text { Beam size } \\
(\mathrm{mm})\end{array}$ \\
\hline Case1 & 21 & 200 & 1 and 3 & $500 \times 500$ & $400 \times 500$ \\
& & & 2 & $1000 \times 1000$ & $1000 \times 900$ \\
Case2 & 30 & 500 & 1 and3 & $500 \times 500$ & $400 \times 500$ \\
& & & 2 & $1000 \times 1000$ & $1000 \times 900$
\end{tabular}

Thickness of wall is $230 \mathrm{~mm}$.

Thickness of the slab is $150 \mathrm{~mm}$.

Thickness of the shear wall is $200 \mathrm{~m}$.

Unite weight of concrete $25 \mathrm{KN} / \mathrm{m}^{2}$.

Grade of concrete is M35.

Table 2: Earthquake parameter

\begin{tabular}{cc}
\hline details & Value \\
\hline $\mathrm{R}$ & 3 \\
$\mathrm{I}$ & 1.5 \\
$\mathrm{Z}$ & 0.16 \\
$\mathrm{Sa} / \mathrm{g}$ & 3 \\
\hline
\end{tabular}

Where,

$\mathrm{Z}=$ zone factor

$\mathrm{Sa} / \mathrm{g}=$ soil type $\mathrm{iii}$

$\mathrm{R}=$ response reduction factor

I= importance factor
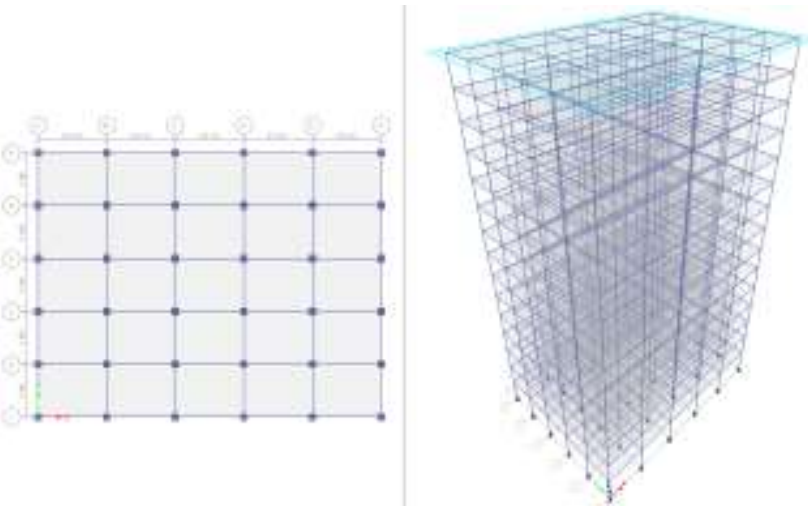

Fig 4: type 1 model

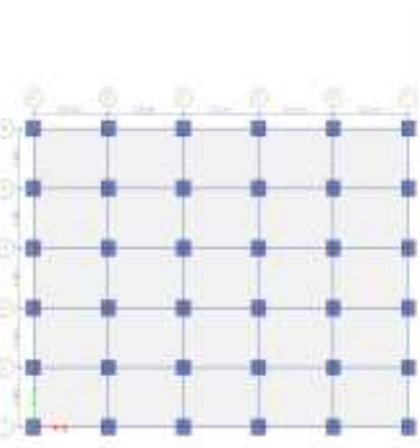

Fig 5: type 2 model

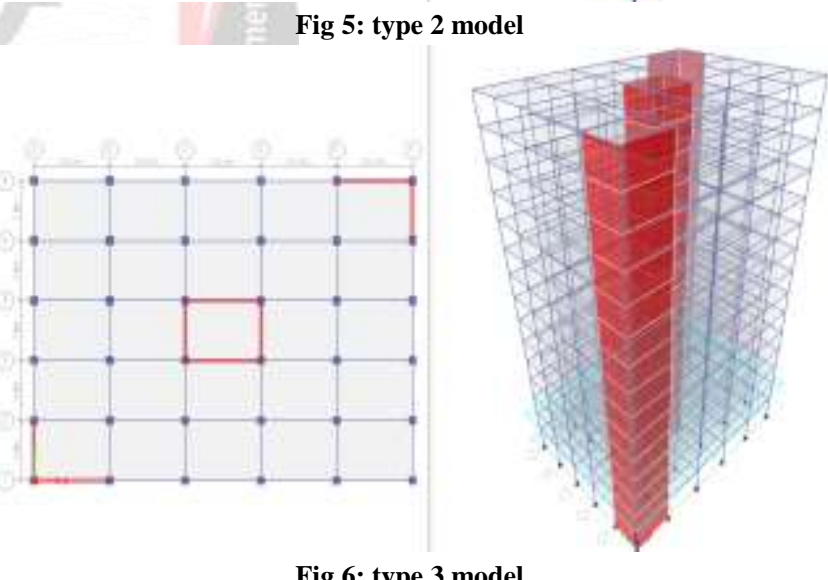

B. Static load

Dead load, live load and earthquake load consider in the all model.

i. Deal load: This load is considered from IS -875 part-11987. Dead load includes the self-weight.

ii. Live load: this load is obtained from code IS-8751987 (PART 2) table 1. 4.0kN/m2 is assumed as the UDL on the building.

iii. Earthquake load: As per code IS 875-1987 part2 from Table1. The structure is assumed to be in 
Zone-II. As per Table 2 of IS 1893 - 2002 zone factor is considered. $5 \%$ damping is assumed, 1.5 as importance factor considered from table 6 of IS 1893-2002.

Response reduction factor $\mathrm{R}$ is considered as 3 in this case. Soil type III, Importance factor is 1.

\section{Load combination:}

This load combination is use in the analysis.

$5 \mathrm{DL}+1.5 \mathrm{WL}$

1.5DL+1.5WL-1.5EQY

$0.9 \mathrm{DL}+0.9 \mathrm{WL}+1.5 \mathrm{EQX}$

$0.9 \mathrm{DL}+0.9 \mathrm{WL}-1.5 \mathrm{EQX}$

$0.9 \mathrm{DL}+0.9 \mathrm{EL}+1.5 \mathrm{EQY}$

$0.9 \mathrm{DL}+0.9 \mathrm{WL}-1.5 \mathrm{EQY}$

$1.5 \mathrm{DL}+1.5 \mathrm{LL}+1.5 \mathrm{WL}$

$1.2 \mathrm{DL}+1.2 \mathrm{LL}+1.2 \mathrm{WL}+1.2 \mathrm{EQX}$

1.2DL+1.2LL+1.2WL-1.2EQX

1.2DL+1.2LL+1.2WL+1.2EQY

1.2DL+1.2LL+1.2WL-1.2EQY

$1.5 \mathrm{DL}+1.5 \mathrm{WL}+1.5 \mathrm{EQX}$

1.5DL+1.5WL-1.5EQX

$1.5 \mathrm{DL}+1.5 \mathrm{WL}+1.5 \mathrm{EQY}$

Table 3: Blast load calculation

\begin{tabular}{|c|c|c|}
\hline characteristics of blast & Case 1 & Case 2 \\
\hline scale distance $(\mathrm{x})(\mathrm{m})$ & 42 & 60 \\
\hline air pressure (pa) & 1 & 1 \\
\hline \multicolumn{3}{|l|}{ pressure } \\
\hline pso & 0.76 & 0.4 \\
\hline pro & 1.97 & 0.93 \\
\hline qo & 0.186 & 0.054 \\
\hline scale time (to) & 1.28 & 1.16 \\
\hline $\mathrm{td}$ & 10.1 & 13.3 \\
\hline $\mathrm{M}$ & 1.285079208 & 1.158817131 \\
\hline $\mathrm{a}$ & 344 & 344 \\
\hline $\mathrm{U}=\mathrm{M}^{*} \mathrm{a}$ & 442.0672476 & 398.633093 \\
\hline \multicolumn{3}{|l|}{ pressure on the building } \\
\hline height (m) & 45.5 & 45.5 \\
\hline $\mathrm{B}$ & 27.5 & 27.5 \\
\hline $\mathrm{L}$ & 20 & 20 \\
\hline \multicolumn{3}{|l|}{$\mathrm{S}=\mathrm{H}$ or $\mathrm{B} / 2$} \\
\hline $\mathrm{s}=\mathrm{H}$ & 45.5 & 45.5 \\
\hline $\mathrm{B} / 2$ & 13.75 & 13.75 \\
\hline whichever is less (s) & 13.75 & 13.75 \\
\hline tc & 93.31159506 & 103.4786141 \\
\hline $\mathrm{Tt}$ & 45.24198548 & 50.17144926 \\
\hline $\operatorname{tr}$ & 124.4154601 & 137.9714855 \\
\hline \multicolumn{3}{|l|}{ tr>td no pre. On backface } \\
\hline \multicolumn{3}{|l|}{ side face } \\
\hline $\mathrm{Cd}$ & -0.4 & -0.4 \\
\hline pso+cd*qo & 0.6856 & 0.3784 \\
\hline \multicolumn{3}{|l|}{ convert to $\mathrm{kn} / \mathrm{m}^{2}$} \\
\hline pro & 19.3257 & 9.1233 \\
\hline Pro $\left(\mathrm{KN} / \mathrm{m}^{2}\right)$ & 193.257 & 91.233 \\
\hline side face pressure & 6.725736 & 3.712104 \\
\hline$\left(\mathrm{KN} / \mathrm{m}^{2}\right)$ & 67.25736 & 37.12104 \\
\hline
\end{tabular}

\section{RESULT AND DISCUSSION}

Case: 1 blast of $200 \mathrm{~kg}$ (TNT) explosive with stand -off distance $21 \mathrm{~m}$.

\section{A. Displacement ( $\mathrm{mm})$}

Earthquake in X- direction.

Table 4: Displacement vs Storey Level (X-Direction)

\begin{tabular}{|c|c|c|c|}
\hline storey & Model-ty1 & Model-ty2 & Model-ty3 \\
\hline 15 & 37.97 & 9.87 & 15.39 \\
\hline 14 & 37.1 & 9.62 & 14.3 \\
\hline 13 & 35.8 & 9.28 & 13.15 \\
\hline 12 & 34.12 & 8.86 & 11.96 \\
\hline 11 & 32.03 & 8.36 & 10.73 \\
\hline 10 & 29.6 & 7.8 & 9.48 \\
\hline 9 & 27 & 7.2 & 8.22 \\
\hline 8 & 24.1 & 6.56 & 6.97 \\
\hline 7 & 21.2 & 5.9 & 5.74 \\
\hline 6 & 18.17 & 5.22 & 4.57 \\
\hline 5 & 15 & 4.54 & 3.46 \\
\hline 4 & 11.9 & 3.86 & 2.45 \\
\hline 3 & 8.7 & 3.18 & 1.57 \\
\hline 2 & 5.65 & 2.5 & 0.85 \\
\hline 1 & 2.63 & 1.71 & 0.32 \\
\hline Base & 0 & 0 & 0 \\
\hline
\end{tabular}

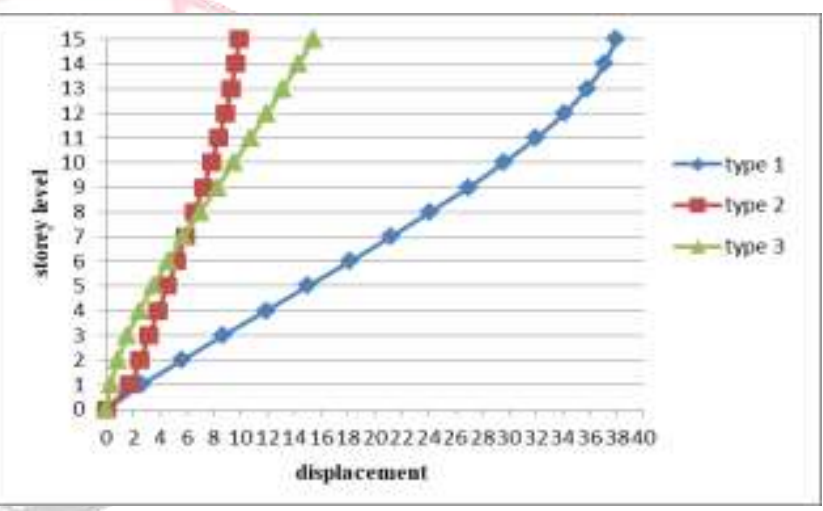

Fig 7: displacement vs storey level ( $\mathrm{x}$ - direction)

As we can see in the above values the displacement gradually decreases as the storey level decreases showing zero at ground floor. When the displacement is compared with three different models it is seen when increase the beam and column size and provide the shear wall displacement is decrease. Displacements are less in modelty 3 when compared to model-ty 2 . The graph is then plotted displacement (mm) with respect to storey level.

\section{Earthquake in $\mathrm{Y}$ - direction.}

Table 5: Displacement vs Storey Level (Y-Direction)

\begin{tabular}{|c|c|c|c|}
\hline storey & Model-ty1 & Model-ty2 & Model ty3 \\
\hline 15 & 33.91 & 9.75 & 18.41 \\
\hline 14 & 30 & 9.42 & 17.22 \\
\hline 13 & 31 & 9.01 & 15.9 \\
\hline 12 & 30 & 8.54 & 14.6 \\
\hline 11 & 28.1 & 8 & 13.22 \\
\hline 10 & 25.9 & 7.41 & 11.7 \\
\hline
\end{tabular}




\begin{tabular}{|c|c|c|c|}
\hline 9 & 23.5 & 6.79 & 10.2 \\
\hline 8 & 21 & 6.14 & 8.8 \\
\hline 7 & 18.4 & 5.48 & 7.31 \\
\hline 6 & 15.7 & 4.82 & 5.86 \\
\hline 5 & 13 & 4.15 & 4.48 \\
\hline 4 & 10.3 & 3.15 & 3.21 \\
\hline 3 & 7.61 & 2.87 & 2.08 \\
\hline 2 & 4.95 & 2.25 & 1.13 \\
\hline 1 & 2.38 & 1.57 & 0.43 \\
\hline base & 0 & 0 & 0 \\
\hline
\end{tabular}

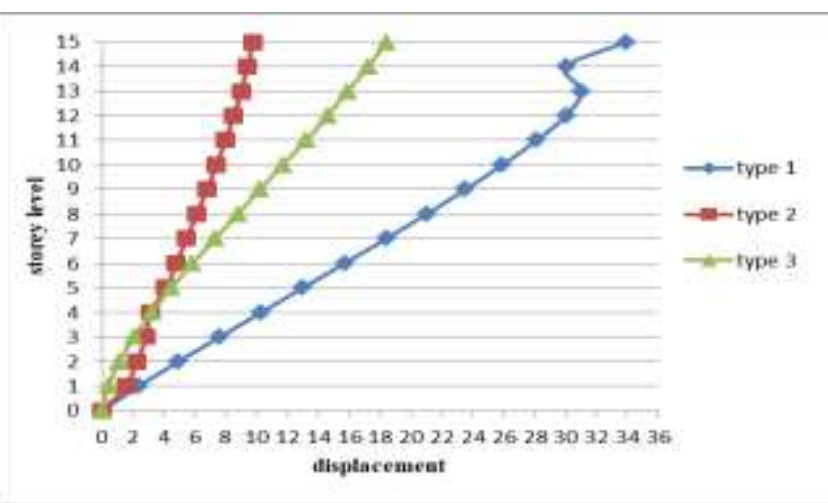

Fig 8: displacement vs storey level (y- direction)

As we can see in the above values the displacement gradually decreases as the storey level decreases showing zero at ground floor. When the displacement is compared with three different models it is seen when increase the beam and column size and provide the shear wall displacement is decrease. Displacements are less in modelty 3 when compared to model-ty 2 . The graph is then plotted displacement $(\mathrm{mm})$ with respect to storey level.

\section{B. Storey drift}

\section{Earthquake in X- direction.}

Fig. 9 represents the storey drifts vs storey level in $y$ direction. The storey drift is observed to be less in type 3 model compare to other models.

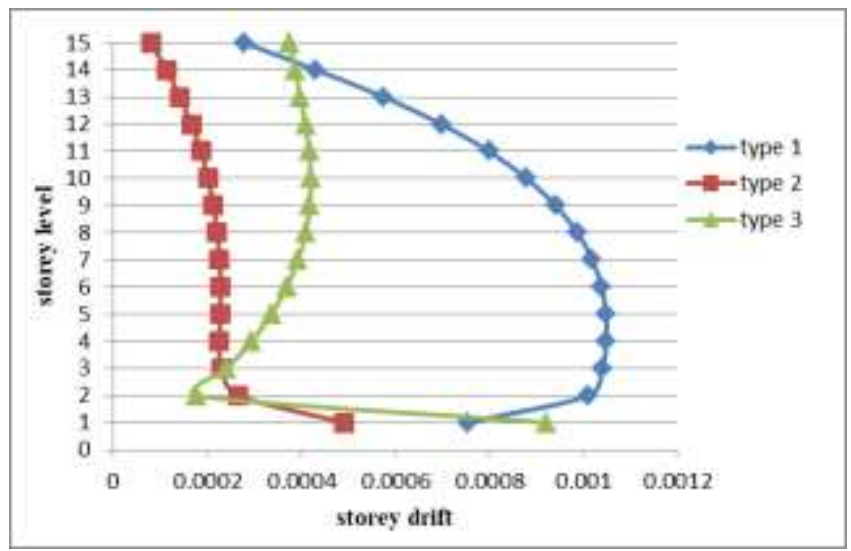

Fig 9: storey drifts vs storey level (x- direction)

\section{Earthquake in Y- direction.}

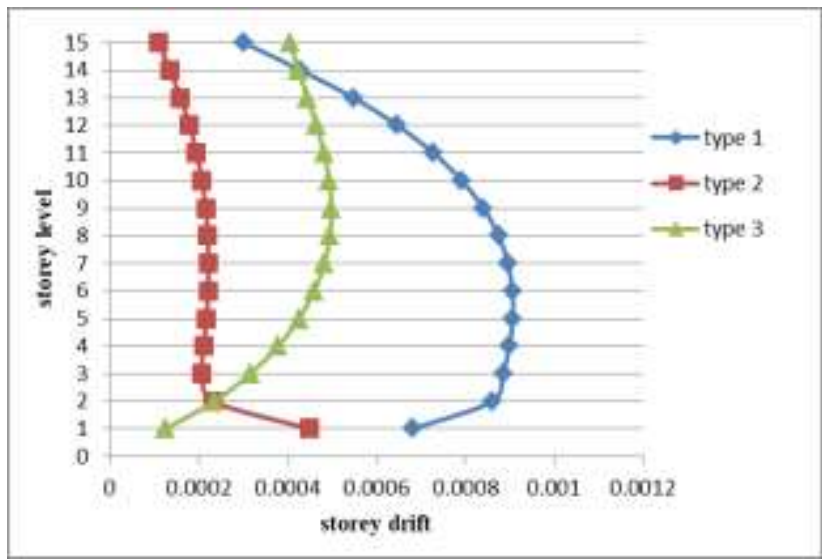

Fig 10: storey drifts vs storey level (y- direction)

As we can see in the above values the storey drift are compared with different models, for earthquake in both $\mathrm{X}$ and $\mathrm{Y}$ directions the storey drift is more in type 1 and less in type 2 . When the 2 and 3 models are compared the storey drift are less in model 3.

C. Storey shear $(K N)$

Table 6: storey level vs Storey Level

\begin{tabular}{|c|c|c|c|}
\hline storey & Model-ty1 & Model-ty2 & Model-ty3 \\
\hline 15 & 322.1174 & 747.8201 & 349.3551 \\
\hline 14 & 625.3685 & 1495.3364 & 697.9371 \\
\hline 13 & 883.7601 & 2132.2733 & 994.9537 \\
\hline 12 & 1100.881 & 2667.4773 & 1244.53 \\
\hline 11 & 1280.319 & 3109.7946 & 1450.792 \\
\hline 10 & 1425.665 & 3468.0716 & 1617.864 \\
\hline 9 & 1540.505 & 3751.1547 & 1749.871 \\
\hline 8 & 1628.43 & 3967.8902 & 1850.939 \\
\hline 7 & 1693.028 & 4127.1244 & 1925.193 \\
\hline 6 & 1737.888 & 4237.7038 & 1976.759 \\
\hline 5 & 1766.598 & 4308.4745 & 2009.761 \\
\hline 4 & 1782.747 & 4348.2831 & 2028.324 \\
\hline 3 & 1789.925 & 4365.9758 & 2036.575 \\
\hline 2 & 1791.719 & 4370.399 & 2038.637 \\
\hline 1 & 1791.719 & 4370.399 & 2038.637 \\
\hline base & 0 & 0 & 0 \\
\hline & & & \\
\hline
\end{tabular}

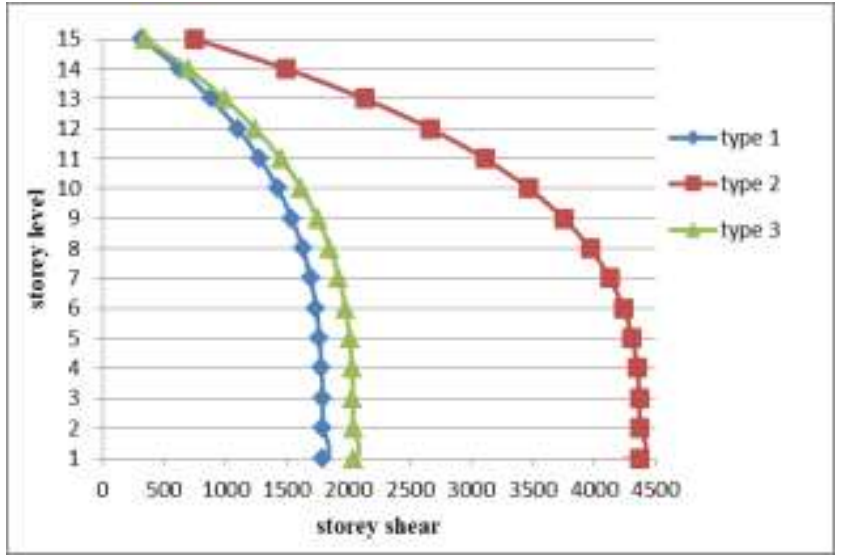

Fig 11: storey shear vs storey level

As we can see in the above values the storey shear which are compared with different models, for storey shear is more 
in type 2 and less in type 3 . When the 2 and 3 type models are compared the storey shear is less in model 3 which is due to the provision of shear walls.

Case: 2 blast of $500 \mathrm{~kg}$ (TNT) explosive with stand -off distance $30 \mathrm{~m}$

\section{A. Displacement}

Analysis of tall building for blast $500 \mathrm{~kg}$ (TNT) explosive with stand -off distance $30 \mathrm{~m}$ has given an idea how to behave a building the earthquake and blast is happen. It is seen that the response of building in $\mathrm{x}$ and $\mathrm{y}$ direction is reduced with increase the beam and column size. When shear wall provide they give more desirable result then increase the beam column size.

\section{B. Storey drift}

The storey drift is less in type 3 model compare to other models.

\section{CONCLUSION}

After completing the present work on analysis of structure subjected to blast effect the flowing conclusion have been made. Important building like embassies, banks, hospital, monumental building, headquarters, historical building, government building, federal building etc. should be designed and analyzed to withstand blast effect within acceptable limits. After analyzed the structure know the top storey have large displacement when compared to bottom storey. As the height of building increase then increase the storey displacement. By increasing beam and column size in structure will improve the blast resistance but it is not practical way to for every situation because huge cross section of beam and column needed to resist blast load. Addition of shear wall gives better blast resistance they give more desirable result and it is economical too compared to other models.

\section{REFERENCES}

[1] Gautham, T.N. and Hegde, M.N., 2017. Blast Resistant Buildings. International Research Journal of Engineering and Technology, 4(9), pp.1156-1159.

[2] Yumnam, N., Raghavendra, N.B., Okram, V. and Samukcham, W., A REVIEW ON STUDY OF MULTISTORY BUILDING SUBJECTED TO BLAST LOADS.

[3] Swathi Ratna, K., 2016. Analysis of RCC and Simon buildings subjected to blast effects. International Research Journal of Engineering and Technology [IRJET] Volume, 7, pp.223-233.

[4] Chandrashekhar, M. and Inamdar, N.S., 2017. ANALYSIS OF BLAST RESISTANCE STRUCTURE.

[5] Arora, H., Hooper, P. A., \& Dear, J. P. (2011). Dynamic response of full-scale sandwich composite structures subject to air-blast loading. Composites Part A: Applied Science and Manufacturing, 42(11), 1651-1662.
[6] Koccaz, Z., Sutcu, F., \& Torunbalci, N. (2008, October). Architectural and structural design for blast resistant buildings. In The 14th World Conference on Earthquake Engineering. Beijing.

[7] Shipsha, A., \& Zenkert, D. (2005). Compression-after-impact strength of sandwich panels with core crushing damage. Applied Composite Materials, 12(3-4), 149-164.

[8] Koccaz, Z., Sutcu, F., \& Torunbalci, N. (2008, October). Architectural and structural design for blast resistant buildings. In The 14th World Conference on Earthquake Engineering. Beijing.

[9] Nourzadeh, D. D., Humar, J., \& Braimah, A. (2017). Comparison of Response of Building Structures to Blast Loading and Seismic Excitations. Procedia engineering, 210, 320-325.

[10] Tang, F., Sun, Y., Guo, Z., Chen, W., \& Yuan, M. (2019). Dynamic responses and energy absorption of hollow sphere structure subjected to blast loading. Materials \& Design, 107920.

[11] Dear, J. P., Rolfe, E., Kelly, M., Arora, H., \& Hooper, P. A. (2017). Blast performance of composite sandwich structures. Procedia engineering, 173, 471-478.

[12] Luccioni, B. M., Ambrosini, R. D., \& Danesi, R. F. (2004). Analysis of building collapse under blast loads. Engineering structures, 26(1), 63-71.

[13] Kashif, Q., \& Verma, M. B. (2014). Effect of Blast on G+ 4 RCC Frame Structure. International Journal of Emerging Technology and Advanced Engineering, 4(11), 145-149.

[14] Shallan, O., Eraky, A., Sakr, T., \& Emad, S. (2014). Response of building structures to blast effects. International journal of engineering and innovative technology, 4(2), 167175.

[15] G. R. Faulhaber, "Design of service systems with priority reservation," in Conf. Rec. 1995 IJREAM Int. Conf. Communications, pp. 3-8.

[16] W. D. Doyle, "Magnetization reversal in films with biaxial anisotropy," in 1987 Proc. INTERMAG Conf., pp. 2.2-12.2-6.

[17] G. W. Juette and L. E. Zeffanella, "Radio noise currents n short sections on bundle conductors (Presented Conference Paper style)," presented at the IJREAM Summer power Meeting, Dallas, TX, Jun. 22-27, 1990, Paper 90 SM 690-0 PWRS.

[18] J. G. Kreifeldt, "An analysis of surface-detected EMG as an amplitude-modulated noise," presented at the 1989 Int. Conf. Medicine and Biological Engineering, Chicago, IL.

[19] J. Williams, "Narrow-band analyzer (Thesis or Dissertation style)," Ph.D. dissertation, Dept. Elect. Eng., Harvard Univ., Cambridge, MA, 1993. 